\section{CANCER RISK IN OIL REFINERY WORKERS: A MORTALITY STUDY IN FOUR ITALIAN PLANTS}

${ }^{1,2}$ Angela Cecilia Pesatori, ${ }^{2}$ Dario Consonni, ${ }^{2}$ Paolo Grillo, 1,2Pier Alberto Bertazzi. ${ }^{1}$ Department of Clinical Sciences and Community Health, University of Milan, Milan, Italy; 'Epidemiology Unit, Department of Preventive Medicine, IRCCS Ca' Granda Foundation, Milan, Italy

\subsection{6/oemed-2014-102362.195}

Objectives To examine the mortality experience of workers employed in four Italian oil refineries.

Method The cohort included 5112 male workers ever employed between 1949 and 2011. The average follow-up period was 49 years. SMR and 95\% CI were calculated using as reference agegender-calendar specific regional rates. Analyses by duration of employment and latency were performed.

Results In the whole cohort, pleural (6 deaths, SMR 1.59; 95\% CI 0.7-3.5), brain cancers (14 deaths, SMR 1.47; 95\% CI 0.92.5 ) and lymphatic leukaemia (LL) (8 deaths, SMR 1.81; 95\% CI 0.9-3.6) showed increased risks. All pleural cancers occurred after 10 years of latency and the highest risk was observed among workers with duration $\geq 20$ years; the brain cancer excess was confined in the shortest duration and latency. The LL excess regarded workers with latency and duration longer than 10 years. Mortality from Non-Hodking lymphoma (NHL) (13 deaths) and acute myeloid leukaemia (AML) did not differ from the expectation. All AML cases (4 deaths) occurred after 20 years of latency (SMR 1.55, 95\% CI 0.6-4.1) and a two foldincreased risk was observed in the longest duration. Mortality for NHL + LL (recently classified as subtypes of NHL) showed increased risks among workers with duration and latency longer than 20 years.

Conclusions Our findings confirmed recent epidemiological evidences of an increased risk for pleural cancer and are coherent with most recent meta-analyses suggesting a limited evidence of an increased risk for lymphatic neoplasms in refinery workers possibly due to past exposure to benzene.

\section{CHILDREN BELOW 5 YEARS OF EMPLOYED MOTHERS ARE LESS EXPOSED TO ACUTE POISONING IN ALEXANDRIA, EGYPT}

Raed Alazab. Alazhar University, College of Medicine, Cairo, Egypt

\subsection{6/oemed-2014-102362.196}

Objectives To identify the incidence rate and determinants of acute poisoning among children (1-60 months old) of employed mothers.

Method A study was conducted at the poisoning unit of a university hospital. The studied children were from both rural and urban areas, were a mix of boys and girls, did not suffer from any mental disabilities, were aged between 1 month old to 60 months old, and were of Egyptian nationality. Data was collected by using a clinical examination form and a questionnaire. All parents/carers of the studied children were interviewed as well. Clinical assessment of the children included: general health conditions; AVPU (alert, respond to verbal stimuli, respond to painful stimuli, unconsciousness); and clinical examinations.

Results $18.5 \%$ of total admissions were children (1-60 months old), $62.5 \%$ were males, $83.3 \%$ did not attend nursery, $79.9 \%$ were from urban areas, $33 \%$ of mothers were illiterate, and $60.2 \%$ of poisonings were due to household products. Kerosene alone was implicated in $24.3 \%$ of all cases; $37.4 \%$ of cases took place in the kitchen; $47.4 \%$ of cases were poisoned during the period between $8 \mathrm{am}$ and $4 \mathrm{pm}$, and $65.4 \%$ reached the poisoning unit within 2 to $4 \mathrm{~h}$ of accidental poisoning. Risk factors among the studied children were ordered by stepwise regression analysis as the following: non employed mothers; children who did not attend nursery; children of the male gender; and the education and literacy level of their mothers.

Conclusions Children of non employed mothers are at more risk for acute poisoning.

\section{ASSOCIATIONS OF THERMOPHILIC ACTINOMYCETES AND NON-TUBERCULOUS MYCOBACTERIA WITH RESPIRATORY HEALTH IN OCCUPANTS OF A WATER- DAMAGED OFFICE BUILDING}

${ }^{1}$ Ju-Hyeong Park, ${ }^{1}$ Jean Cox-Ganser, 'Sandra White, ${ }^{1}$ Scott Laney, ${ }^{2}$ Steve Caulfield, ${ }^{2}$ William Turner, ${ }^{3}$ Austin Sumner, ${ }^{1}$ Kathleen Kreiss. ${ }^{1}$ National Institute for Occupational Safety and Health, Morgantown, WV, USA; ${ }^{2}$ Turner Building Science and Design, LLC, Harrison, ME, USA; ${ }^{3}$ Northwestern Occupational Health, Albans, VT, USA

\subsection{6/oemed-2014-102362.197}

Objectives We examined microbial correlates of health outcomes in employees in a building with a sarcoidosis cluster and excess asthma.

Method We offered employees a questionnaire and pulmonary function tests (PFT) and collected 120 floor dust samples by vacuuming workstation areas or the exterior rim of the floor. We analysed dust for culturable fungi, bacteria, actinomycetes, non-tuberculous mycobacteria, and cell wall components of fungi $[(1 \rightarrow 3)-\beta$-D-glucan $]$ and Gram-negative bacteria (endotoxin).

Results Among 136 employees, 77\% participated in the questionnaire, $64 \%$ in PFTs, and $49 \%$ in both. Of the 105 questionnaire participants, $50(48 \%)$ reported at least one hypersensitivity pneumonitis (HP)-like symptom (shortness of breath on exertion, flu-like achiness, or fever and chills) in the last 4 weeks; 69 (66\%) reported at least one HP-like symptom in the last 12 months. PFT results were abnormal or borderline for 13 participants ( 6 obstruction; 2 restriction; 2 mixed pattern; and 3 borderline obstruction). In multivariate logistic regressions, log-transformed levels of thermophilic actinomycetes $\left(\mathrm{GM}=580 \mathrm{CFU} / \mathrm{m}^{2}\right)$ were positively associated with HP-like symptoms in the last 4 weeks [odds ratio $(\mathrm{OR})=1.6,95 \%$ confidence interval $(\mathrm{CI})=1.15-2.35]$ and 12 months $(\mathrm{OR}=1.6,95 \%$ $\mathrm{CI}=1.09-2.32$ ), and with an abnormal/borderline PFT result $(\mathrm{OR}=1.7,95 \% \mathrm{CI}=1.04-2.88)$. Log-transformed mycobacteria levels $\left(\mathrm{GM}=960 \mathrm{CFU} / \mathrm{m}^{2}\right)$ were marginally positively associated with HP-like symptoms in the last 4 weeks that improved when away from the building $(\mathrm{OR}=1.9 ; 95 \% \mathrm{CI}=0.95-3.85)$. These associations were not confounded by smoking, gender, age, or building tenure.

Conclusions Our study suggests that thermophilic actinomycetes and non-tuberculous mycobacteria may have played a role in the respiratory illness among occupants of this water-damaged building.

\section{BENIGN PLEURAL ABNORMALITIES AND MESOTHELIOMA AMONG ASBESTOSIS WORKERS IN HONG KONG}

${ }^{1}$ Lap Ah (Shelly) Tse, ${ }^{2}$ Ronald KF Au, ${ }^{1}$ Minghui Chen, ${ }^{1}$ Feng Wang, ${ }^{1}$ Ignatius TS Yu. ${ }^{1} J C$ School of Public Health and Primary Care, The Chinese University of Hong Kong, Hong Kong, China; ${ }^{2}$ Pneumoconiosis Clinic, Department of Health, Hong Kong, China

10.1136/oemed-2014-102362.198 